\title{
Editor-in-chief's note: transportation security 10 years on
}

\author{
Andrew R. Thomas ${ }^{1}$
}

Published online: 21 May 2018

(C) Springer Science+Business Media, LLC, part of Springer Nature 2018

This issue marks the 10th anniversary of the Journal of Transportation Security. I thought it would be important to review how things have unfolded- and where the Journal stands as we look into the future. Ten years seems a good marker to measure how one's thoughts and intentions have played out over time.

When the idea for a peer-reviewed journal on the subject of transportation security emerged, it was clear that new territory was going to be blazed. Good scholarly research had been done for years on topics related to transportation security. Yet, deserved recognition of much of that research was short-changed, as it was hidden away within the particular silos that dominate much of academe, and society, today.

The purpose in creating JTRS was to provide a platform for all kinds of looks into the subject, which could be easily disseminated to a broader audience. As we've seen, 9/11 and subsequent events have compelled people around the world to recognize transport security as more than merely a single element of the global networks that move people and goods. Once a routine component of modern transportation, security now represents a vital necessity in many areas and an urgent national- and international- priority. From the beginning, the mission of JTRS was - and remainsto disseminate new research, thought, and analysis for teachers, researchers, policy makers and practitioners who view transportation security as a critical element in the post 9/11 world.

The challenge in meeting the mission of JTRS was a tough one. It required a way of thinking about research that is not often widely found. Instrumental was embracing a multidisciplinary approach right from the outset. A real concern was that if one specific area of specialization could come to dominate transpiration security, researchers in other areas would be reluctant to share their ideas. To that end, it was believed the Editorial Board should reflect a diversity of background and perspective. Currently, the Editor-in-Chief comes from international business; while the Associate Editors represent the fields of engineering, political science, supply chain management, psychology,

Andrew R. Thomas

art@uakron.edu

1 University of Akron, Akron, OH, USA 
and military studies. The other members of the Editorial Board come from equally varied points-of- view, including law, criminology, economics, counterterrorism, nuclear science, history, logistics, and media studies. Moreover, as much of transportation security is a global endeavor, particular attention was paid in assembling an Editorial Board that reflected this international dimension. While the Editor-in-Chief is from the U.S., two-thirds of all Editorial Board members represent more than two-dozen other nations, including four of the six Associate Editors.

Critically, this diversity of the Editorial Board in both areas of specialty and geography has been reflected in the 183 articles published to date. At least 10 articles have been published from each of these varied areas of specialization:

- Legal studies

- Supply chain management

- Engineering and technology

- Maritime and ocean transport

- Economics and business

- Emergency management

- Criminology

- Rail and mass transit

- Aviation security

- Geopolitics

- Public policy

- Education and knowledge management

- Cybersecurity and space

- Road and inland transport

Equally noteworthy, published articles in JTRS originated from more than 40 countries on six continents.

While all of this may appear to be bragging - and maybe some of it is- the numbers of the past also reveal that the future looks bright. In the coming years, transportation security will keep evolving as both a scholarly discipline and an essential part of our lives. Continued openness to new ideas- wherever they come from- will be vital to building a robust and dynamic discipline that serves the needs of practicioners and researchers alike.

On a personal level, looking back over the past 10 years, I find myself rationally optimistic about both the present and future of JTRS. A decade ago, we waded into unknown waters: where we were headed, no on really knew. There were inevitably many twists and turns along the way. Still, the commitment to diversity of thought and background kept us balanced and afloat. I am confident the coming years will see even greater progress, as we strive to shape something unique and important to our world. 